\title{
Resistance of a sub-arctic bird community to severe forest damage caused by geometrid moth outbreaks
}

\author{
Ole Petter Laksforsmo Vindstad ${ }^{1} \cdot J^{\prime}$ Und Jepsen ${ }^{2} \cdot$ Rolf Anker Ims $^{1}$
}

Received: 13 January 2015/Revised: 20 April 2015/Accepted: 23 April 2015/Published online: 1 May 2015

(C) The Author(s) 2015. This article is published with open access at Springerlink.com

\begin{abstract}
Outbreaks by geometrid moths periodically cause mass mortality of trees and state changes in understorey vegetation in sub-arctic mountain birch forest in northern Scandinavia. In order to assess the short-term impacts of such disturbance on forest bird communities, we took bird censuses in forest where almost all birch trees had been killed by moth outbreaks $2-4$ years before the study and in undamaged forest. The study was repeated in two locations (Kirkenes and Tana) with contrasting forest structure and fragmentation. Using a hierarchical community model, we show that the total abundance of birds in Kirkenes was only about $25 \%$ lower in damaged than undamaged forest and that species richness differed even less between the two forest types. Meanwhile, neither bird abundance nor species richness differed between damaged and undamaged forest in Tana. The observed patterns in abundance were mainly driven by a few very common species. Only a single species showed indication of being more abundant in damaged forest. Thus, our findings indicate that bird communities in sub-arctic mountain birch forest have a high degree of resistance to forest damage caused by moth outbreaks. We suggest that bird
\end{abstract}

Communicated by Jarmo Holopainen.

Electronic supplementary material The online version of this article (doi:10.1007/s10342-015-0886-y) contains supplementary material, which is available to authorized users.

Ole Petter Laksforsmo Vindstad

ole.p.vindstad@uit.no

1 Department of Arctic and Marine Biology, University of Troms $\emptyset, 9037$ Troms $\varnothing$, Norway

2 Norwegian Institute for Nature Research, Fram Centre, 9296 Troms $\varnothing$, Norway populations in outbreak-affected forest may be maintained by surviving trees and by standing dead tree trunks, which help maintain the vertical structure of the forest habitat. The fact that many of the studied bird species are habitat generalists may also explain their apparently weak responses to the damage caused by the outbreak. Our results do not point towards forest damage caused by moth outbreaks as a major driver of change in bird communities in the study system, although more long-term research is needed to substantiate this conclusion.

Keywords Disturbance - Mountain birch - Operophtera . Epirrita $\cdot$ Transect $\cdot$ Hierarchical model

\section{Introduction}

Outbreaks by pest insects are major sources of disturbance in many forest ecosystems (Barbosa et al. 2012). Outbreaks can cause damage and mortality in trees and understorey vegetation across enormous areas and thereby alter many biotic and abiotic attributes of forest habitats, including the amount of canopy cover (Dennison et al. 2010; Moulinier et al. 2013), the spatial heterogeneity of the habitat (Müller et al. 2008; Yang 2012) and the species composition of vegetation communities (Man and Rice 2010; Karlsen et al. 2013). This, in turn, may alter habitat quality for a wide range of forest-dwelling taxa (Lehnert et al. 2013). However, the consequences of this have so far been studied for relatively few species, and there are still large uncertainties as to how outbreak-induced changes in habitat characteristics affect wildlife communities in most outbreak-affected systems. The importance of such impact studies is currently accentuated for boreal and sub-arctic forest ecosystems, where insect outbreaks recently appear to have become 
more extensive due to climate change (Jepsen et al. 2008, 2011; Weed et al. 2013).

Birds are one group of organisms that are known to be sensitive to habitat changes caused by insect outbreaks. Many species of birds forage, seek shelter from predators and build their nests in trees or among understorey vegetation. The severe impacts that outbreaks have on forest vegetation can thereby cause cascading effects on bird communities in outbreak-affected areas. Bird species which are associated with closed-canopy forest have typically been found to undergo population declines in areas experiencing outbreak-induced mortality of trees, while species that prefer clearings and disturbed habitats have usually been found to increase (Rabenold et al. 1998; Gale et al. 2001; Becker et al. 2008). The same is true for species associated with the understorey vegetation, which often grows denser and taller after outbreaks, probably due to increased amounts of light reaching the forest floor or fertilization from insect frass and cadavers (Bell and Whitmore 1997; Canterbury and Blockstein 1997).

In northern Scandinavia, outbreaks by the two geometrid moths (Lepidoptera: Geometridae) autumnal moth (Epirrita autumnata) and winter moth (Operophtera brumata) periodically cause defoliation of mountain birch (Betula pubescens ssp. czerepanovii) across areas of 1000s of square kilometres (Jepsen et al. 2009a, 2013). Moth larvae are an important food resource for many species of birds in the mountain birch forest, and several bird species appear to increase reproductive effort due to a superabundance of food in moth outbreak years (Enemar et al. 1984, 2004; Hogstad 2005; Lindström et al. 2005). Spatiotemporal variation in the amplitude of moth outbreaks (and hence the availability of moth larvae) has also been proposed as a driver of breeding nomadism in some bird species (Lindström 1987). Thus, by affecting food supply, outbreaks can induce short-term changes in the structure of local bird communities, with both the number of bird species and their relative abundances being altered during outbreak years (Enemar et al. 2004). However, while the responses of bird communities to outbreak-induced changes in food supply are relatively well understood, little is known of how birds are affected by the disturbance that outbreaks cause to forest vegetation. Moth outbreaks can cause mass mortality of mountain birch across enormous areas, with mortality rates of birch stems sometimes exceeding $95 \%$ locally (Jepsen et al. 2009a, 2013). Since the forest in northern Scandinavia is strongly dominated by mountain birch, this causes a precipitous decline in the number of living trees in the landscape. This would be expected to have negative impacts on bird species that forage in the foliage of the tree canopy or the tall shrub layer. The outbreaks also induce state shifts in the field layer of the understorey vegetation, with the typically dominant dwarf shrubs black crowberry (Empetrum nigrum ssp. hermaphroditum) and bilberry (Vaccinium myrtillus) being replaced by the graminoid wavy hair grass (Avenella flexuosa) within a few years of the conclusion of outbreaks. Meanwhile, there is little regrowth in the tall shrub layer, so that the understorey generally remains very open and dominated by grass at least within the first decade after an outbreak (Jepsen et al. 2013; Karlsen et al. 2013). It is difficult to predict a priori how this transition from a dwarf shrub to a grass-dominated field layer will affect birds that are mainly associated with the understorey vegetation. Importantly, all of these changes to the vegetation are much more persistent than the transient increase in food supply that birds experience during outbreak years. Although the recovery time of the birch forest ecosystem after a severe outbreak is not known in detail, the timescale of this process is on the order of several decades. Thus, outbreak-induced forest damage may have long-term consequences for bird communities in affected areas.

Understanding the responses of birds to outbreak-induced forest damage is currently a matter of increasing concern. Between 2002 and 2008, northern Scandinavia experienced the most severe period of moth outbreak activity that has so far been documented. Approximately 10,000 square $\mathrm{km}$ of mountain birch forest suffered heavy defoliation at least once during this period, and extensive mortality of birch occurred in many areas (Jepsen et al. 2009a). During the same period, several of the most common bird species in the mountain birch forest underwent region-wide declines in Scandinavia (Lehikoinen et al. 2014). The extensive forest damage caused by the recent outbreaks may have been a contributing factor to the avian population declines. However, no study has investigated the response of bird communities to outbreak-induced forest damage. In the present study, we address this knowledge gap by comparing bird abundance and species richness between healthy, undamaged birch forest and forest that was heavily damaged by a moth outbreak 2-4 years before the outset of the study. By means of this spatial contrast, we assess the short-term responses of bird communities to outbreak-induced forest damage. Moreover, in order to assess the consistency of bird community responses to the outbreak, we repeat the study in two locations that differ in terms of forest structure and fragmentation.

\section{Materials and methods}

\section{Study region}

The study was conducted in the Varanger region (approximately $70^{\circ} \mathrm{N}, 29^{\circ} \mathrm{E}$ ) in Finnmark County, northern 
Norway (Fig. 1). This region lies in a transition zone between sub-arctic deciduous forest and low-arctic tundra and has mean temperatures of -12.2 and $12.3^{\circ} \mathrm{C}$ for January and July, respectively [Rustefjelbma meteorological station $\left(70^{\circ} 23^{\prime} 55^{\prime \prime} \mathrm{N}, \quad 28^{\circ} 11^{\prime} 36^{\prime \prime} \mathrm{E}\right), \quad 1961-2000$ normal period]. Mountain birch is by far the most common tree species, and forests of this tree form an ecotone between the boreal coniferous forest to the south and the tundra to the north. Patches of aspen (Populus tremula) and Scots pine (Pinus sylvestris) also occur locally. The Varanger region has recently experienced severe outbreaks first by the autumnal moth in 2002-2004 and subsequently by the winter moth in 2005-2009, causing extensive mortality of mountain birch throughout the region (Jepsen et al. 2009a, 2013).

\section{Study design and bird censuses}

The study was replicated in two locations located approximately $70 \mathrm{~km}$ apart, namely Tana $\left(70^{\circ} 03^{\prime} \mathrm{N}, 27^{\circ} 45^{\prime} \mathrm{E}\right)$ and Kirkenes $\left(69^{\circ} 46^{\prime} \mathrm{N}, 2^{\circ} 20^{\prime} \mathrm{E}\right)$, which were defoliated mainly during 2006-2007 and 2007-2009, respectively (Fig. 1). Note that the moth outbreak had collapsed in both locations at the outset of the study (2011), so we have no reason to believe that our results were influenced by increased availability of moth larvae for insectivorous birds in outbreak-affected forest. The birch forest in both Tana and Kirkenes is of an oligotrophic type (Karlsen et al. 2013), where most of the trees are polycormic (multistemmed) and rather small, with individual stems rarely being taller than 6-7 m. However, relatively speaking, Kirkenes has a richer forest type, with a clear tendency towards fewer and larger stems per tree than in Tana (Fig. $\mathrm{S} 1$ in Appendix 1 of ESM). The birch forest in Tana forms large continuous tracts across several $\mathrm{km}$ and is rarely interrupted by other habitat types. The forest in Kirkenes is much more fragmented, with frequent interruptions by mires and rocky areas. Our study area in Kirkenes is also located within $40 \mathrm{~km}$ the of pine forest taiga zone further south, while there are no substantial occurrences of coniferous forest within $100 \mathrm{~km}$ of Tana.

During the spring of 2011, we established a sampling transect in both Tana and Kirkenes. Both transects had ten sampling sites, which were arranged in a roughly linear manner and interspaced by approximately $2 \mathrm{~km}$. The Kirkenes transect was slightly curved towards the end, so

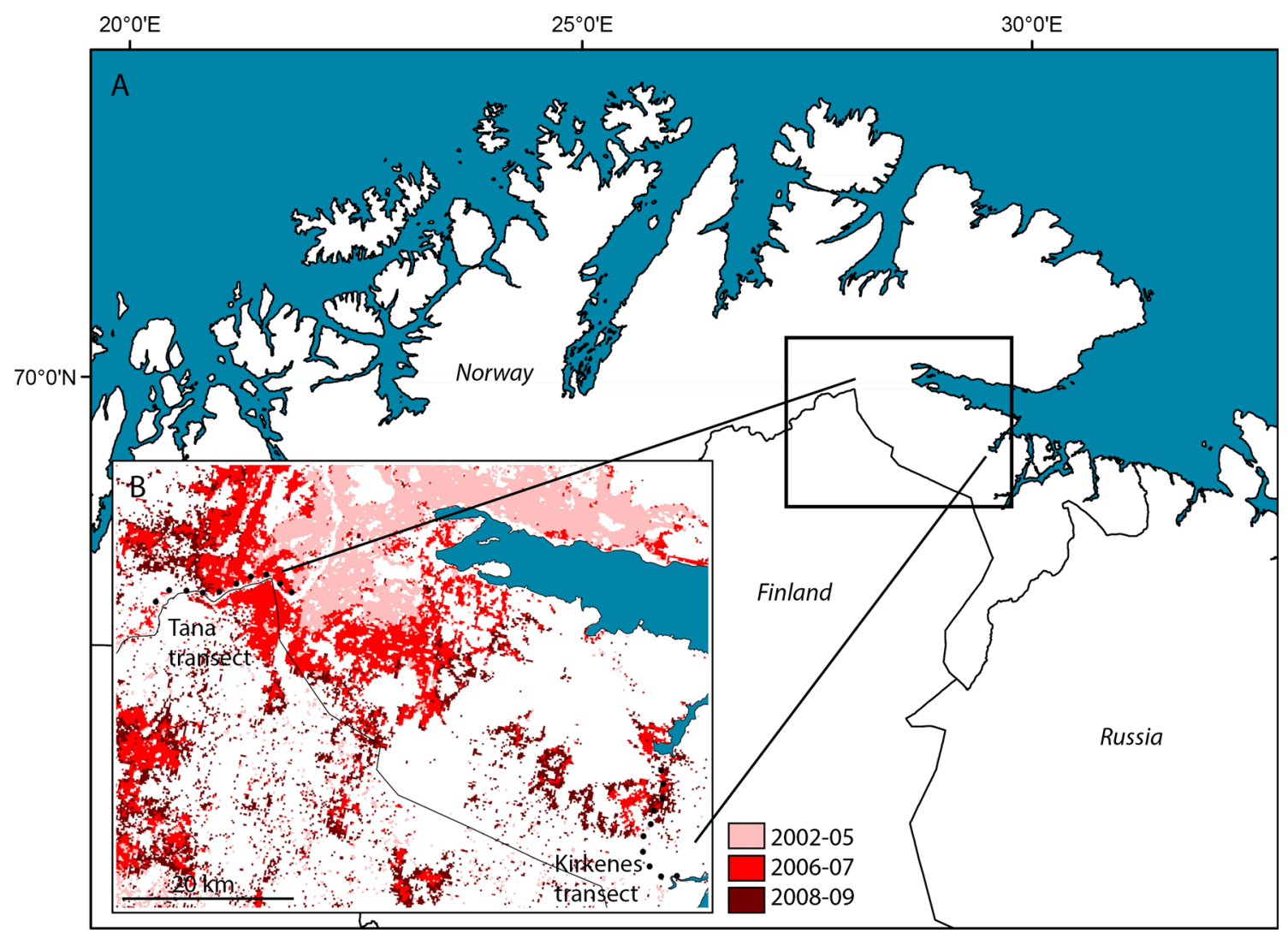

Fig. 1 Map of Finnmark County with the study region in Varanger inset. Red areas represent birch forest which experienced severe defoliation during the most recent moth outbreak. Different shades indicate the main years of defoliation for different areas (see key). The sampling sites of the two transects (Kirkenes and Tana) are indicated by black dots 
that the last two sites were located at about the same distance from site 1, although still being $2 \mathrm{~km}$ apart. Both transects started in forest which had experienced extensive mortality of birch due to the moth outbreak and ran towards forest which had not suffered substantial defoliation (Fig. 1). The overall locations of the transects were chosen based on satellite-derived maps of defoliation intensity (Jepsen et al. 2009b) and proximity to roads, in order to ensure accessibility (no site was located more than about $1.5 \mathrm{~km}$ from a road). The exact locations of the individual sampling sites were subsequently chosen on the ground, using a GPS to achieve correct spacing of sites. To provide a local measure of forest damage for the individual sites, two survey lines were established within each site. The lines started at the centre point of the site and ran for $50 \mathrm{~m}$ towards the north and south, respectively. We selected the closest birch tree (standing or fallen) every $7 \mathrm{~m}$ along the lines and visually scored the damage of its three thickest stems according to the criteria in Table 1 . To quantify local forest structure, we also measured the diameter of each of these stems at breast height (1.3 m above the ground) and counted the total number of stems in each selected tree. Only stems which were more than $1.3 \mathrm{~m}$ in height were included in these measurements, and trees without such stems were not selected.

The site-specific damage scores showed that the great majority of stems were dead or heavily damaged at site 1-4 in Kirkenes and site 1-6 in Tana (Fig. 2a, b). Hence, we designated these sites as "damaged". Most of the stems at the remaining sites were alive and either undamaged or with light loss of foliage (which is typical for normal, healthy mountain birch forest). Accordingly, these sites were designated as "undamaged". This classification of sites as damaged or undamaged (or equivalently inside or outside the outbreak area) was used to represent forest damage in the subsequent analyses. The appearance of a typical undamaged and damaged site in 2011 is shown in Fig. 2c, d, respectively. Note that the levels of forest damage recorded at the individual sites were representative not only for the $50 \mathrm{~m}$ radius in which birch stems were measured, but also for the surrounding landscape at much larger scale (Fig. 1; Jepsen et al. 2009a). Thus, within each transect, damaged and undamaged sites should be considered as spatial replicates within a single continuous area of damaged and undamaged forest, respectively.
Bird censuses were taken within a 3-day period between 25 June and 1 July in the years 2011-2013. The census period represents the early part of the breeding season, and thus the period of peak activity, for birds in this high-latitude community. The sun never sets in the study region during summer, but birds sing most actively between 1900 and $2300 \mathrm{~h}$ in the evening and 0200 and $1000 \mathrm{~h}$ in the morning (Hausner et al. 2003; Ratcliffe 2005). Censuses were therefore taken mainly during these periods. All sampling sites were visited three times per year (for a total of nine visits per site), with the timing of the visits being alternated between sites, to avoid that some sites were consistently sampled earlier or later in the day than others. During each visit, the observer stood at the centre of the site and recorded all birds that could be seen or heard from this point (irrespective of distance) during a 15 -min period. The number of individuals recorded for a given bird species was taken as a species-specific index of abundance for the site. Because the probability and range and of detection may vary considerably among bird species, the value of this index should not be viewed as an estimate of bird density that can directly compared between species. However, this was a minor concern for our study, since our main goal was to conduct within-species comparisons of abundance between damaged and undamaged birch forest. The bird censuses were taken by the same experienced observer in all 3 years.

We were mainly interested in how outbreak-induced forest damage affected bird species that use the mountain birch forest as their main habitat. Thus, typical wetland birds such as ducks and waders were excluded from the dataset. The rough-legged buzzard (Buteo lagopus) was also excluded, since the home range of this large bird of prey can exceed the 2-km distance between our samplings sites, potentially resulting in detections of single individuals at several sites. For all other bird species in the dataset, we assumed that the distance between sites was adequate to avoid this problem. Thus, we also assumed that the bird communities observed at the individual sites were independent of each other.

As outlined in the introduction, we expected that bird species which mainly utilize the tree canopy would be negatively affected by outbreak-induced mass mortality of birch trees. Meanwhile, it is more difficult to predict how birds that are mainly associated with the understorey

Table 1 Classification system used to score the damage of birch stems

\begin{tabular}{llc}
\hline Damage category & Definition & Damage score \\
\hline Living: undamaged & Stem with no apparent loss of foliage & 1 \\
Living: lightly damaged & Stem with $>50 \%$ of foliage reaming compared to healthy stem & 2 \\
Living: severely damaged & Stem with $<50 \%$ of foliage reaming compared to healthy stem & 3 \\
Dead & Dead stem without foliage & 4 \\
\hline
\end{tabular}



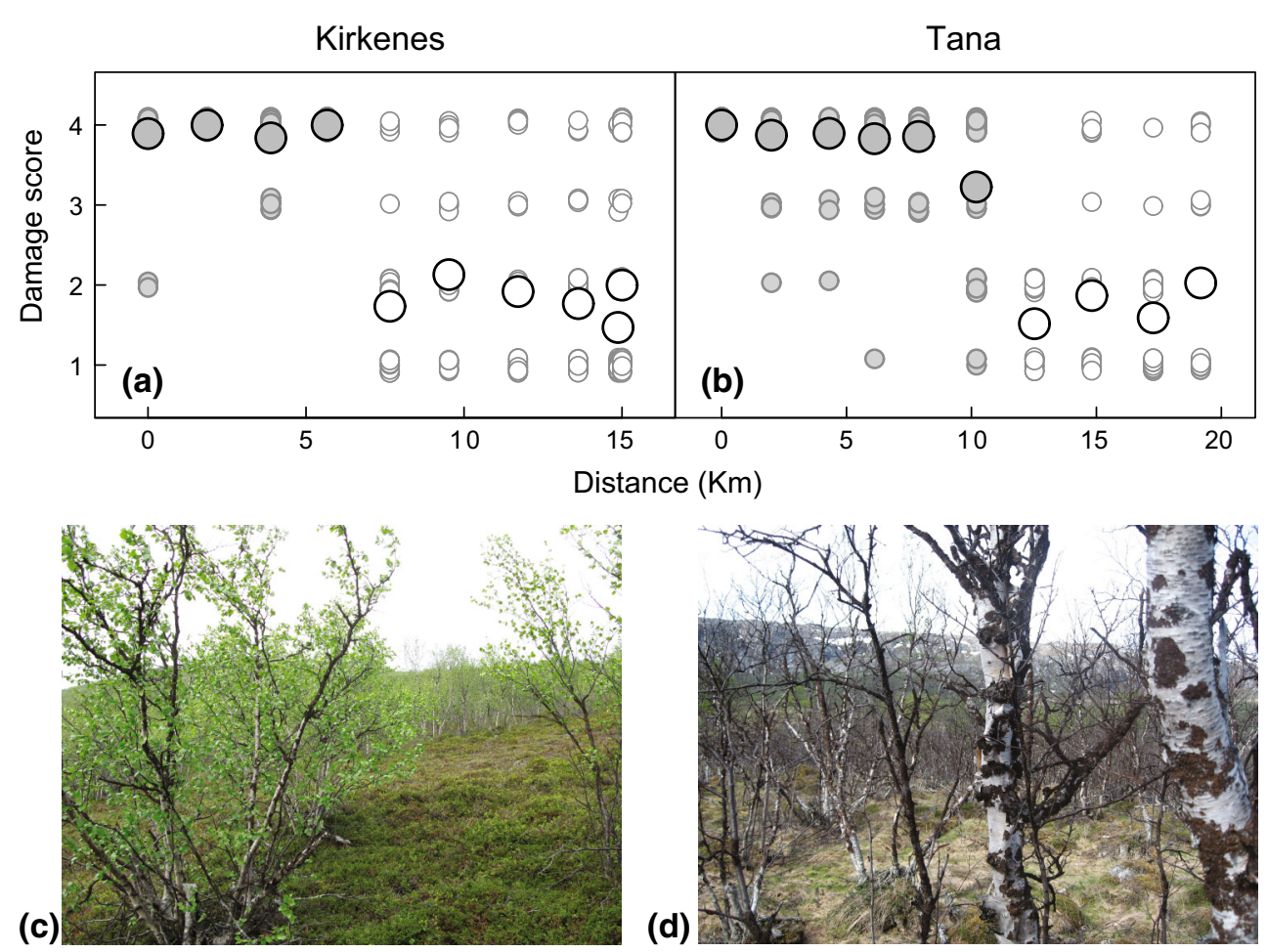

Fig. 2 Damage scores of birch stems (see Table 1 for explanation) for each sampling site in Kirkenes (a) and Tana (b), plotted against the airline distance from the first site in each transect. Small circles represent damage scores for individual birch stems, while large circles represent mean scores for each site. To prevent the scores for individual stems from landing directly on top of each other, a small amount of random variation was added to the stem-specific scores

vegetation should be expected to respond to the transition from dwarf shrub to grass-dominance that occurs in the field layer after outbreaks. To assess whether there was empirical evidence for differential responses to outbreaks in bird species that utilize different layers of the forest vegetation, we broadly classified all species as foraging mainly in trees or on the ground, according to Snow et al. (1998).

\section{Statistical analyses}

We used a hierarchical community model to investigate how the abundance and species richness of birds varied between damaged and undamaged forest. A major advantage of such models is that they allow the true (unknown) underlying ecological state of a system (such as abundance) to be estimated, while accounting for imperfect detection of the study organisms during sampling [see Iknayan et al. (2014) for a recent review].

We conducted the analysis by extending the $\mathrm{N}$-mixture model of Royle (2004) to a multi-species setting, as exemplified by Yamaura et al. (2012) and Chandler et al. (2013). We assumed that the true abundance $\left(N_{i, j, k}\right)$ of using the jitter function in R. Sites designated as damaged and undamaged are indicated by grey and white, respectively. The photographs show a typical sampling site in undamaged (c) and damaged (d) forest on the same day in early June of 2011. Note that the dominance of grass in the field layer in damaged forest is not readily apparent in $\mathbf{d}$ because the photographs are taken relatively early in the growing season of our high-latitude study system

species $i$ at site $j$ in year $k$ resulted from a Poisson process with parameter $\lambda_{i, j, k}$. Thus, the main goal of the analysis was to assess how $\lambda$ (and thereby $N$ ) differed between damaged and undamaged forest. In addition, owing to the contrasting habitat characteristics of Kirkenes and Tana, we suspected that the overall abundance of birds and the effects of forest damage on abundance, might differ between the two locations. Accordingly, our model had separate intercepts and damage effects for each location. Specifically, we assumed that:

$\log \left(\lambda_{i, j, k}\right)=\beta 0_{i, \text { location }[j]}+\beta 1_{i, \text { location }[j]} \times \operatorname{Dam}_{j}$

where location[j] indicates whether site $j$ is located in Kirkenes or Tana, and $\mathrm{Dam}_{j}$ is a dummy variable that is equal to 1 if site $j$ is located in damaged forest and 0 otherwise. The inverse logarithm of the intercept $\beta 0_{i, \text { location }[j]}$ is the expected abundance of species $i$ at sites in undamaged forest for the location in question, and $\beta 1_{i, \text { location }[j]}$ is the effect on the abundance for species $i$ when moving to sites in damaged forest within the same location.

We assumed that the observed count $\left(n_{i, j, k, l}\right)$ for species $i$ at visit 1 to site $j$ in year $k$ was the result of a binomial process with probability parameter $p_{i, j, k, l}$ and number of 
trials equal to $N_{i, j, k}$ (i.e. the estimated number of individuals present). We expected that the detection probability $(p)$ would vary between Kirkenes and Tana, but we had no reason to expect that the effect of forest damage on detection probability would be location specific. Thus, we assumed that:

$\operatorname{Logit}\left(p_{i, j, k, l}\right)=\alpha 0_{i, \text { location }[j]}+\alpha 1_{i} \times \operatorname{Dam}_{j}$

i.e. the coefficient for forest damage was not location specific. The inverse logit of the intercept $\alpha 0_{i, \text { location }[j]}$ is the probability of detecting an individual of species $i$ at sites in undamaged forest in location $l$, and $\alpha 1_{i}$, is the effect on detection probability for species $i$ when moving to sites in damaged forest.

The species richness at site $j$ in year $k$ was computed by converting the matrix of estimated abundances $\left(N_{i, j, k}\right)$ to the presence/absence format ( 1 if $N>0$ and 0 otherwise) and summing the resulting matrix across all species for each combination of $j$ and $k$ (Yamaura et al. 2012).

$\mathrm{N}$-mixture models assume that sampling sites have closed populations (i.e. no immigration, emigration, births or deaths). In our case, $\lambda$ was allowed to vary between the study years, hence allowing year-specific estimates of abundance for each site. Thus, we only assumed population closure for the sites across the three visits within years. We expect this assumption to hold approximately, since most of the bird species in our data are territorial during the breeding season.

As is conventional for hierarchical community models, the model coefficients of the individual species were assumed to be random effects, drawn from common community-level distributions defined by so-called hyperparameters (Iknayan et al. 2014). For instance, we assumed that $\beta 1_{i, \text { Kirkenes }}$ was drawn from a normal distribution with mean $\mu_{\beta 1 \text {,Kirkenes }}$ and standard deviation $\sigma_{\beta 1 \text {,Kirkenes }}$ (and so on for the other coefficients). $\mu_{\beta 1 \text {,Kirkenes }}$ can be interpreted as the overall community response (mean across species) to forest damage in Kirkenes, and $\sigma_{\beta 1 \text {,Kirkenes }}$ is the standard deviation (SD) of this response among species. Thus, to obtain community-level summaries for the different model coefficients, we estimated the mean $(\mu)$ and $\mathrm{SD}(\sigma)$ (i.e. the hyper-parameters) of the distributions of each coefficient during the model fitting process (Kéry and Royle 2009; Zipkin et al. 2009). Note that we assumed separate distributions for coefficients for Kirkenes and Tana, since we expected that bird dynamics might differ between the two locations.

The model was analysed using Markov chain Monte Carlo (MCMC) simulations run in WinBUGS version 1.4.3 (Sturtz et al. 2005), using the R2WinBUGS library as an interface to $\mathrm{R}$ version 2.15.2 (R Development Core Team 2012). We ran five parallel chains with 60,000 iterations, discarded the first 20,000 as burn-in, and thinned the chains by ten. The convergence of the model was assessed by the Rhat statistic, which should take a value of 1.10 or less for a parameter that has converged (Gelman and Hill 2007). Rhat was $<1.08$ for all of the parameters in our model and $<1.03$ in the great majority of cases. Thus, model convergence was deemed to be adequate. The means of the posterior distributions were taken as point estimates of the parameters being investigated. We used similar uninformative priors as Yamaura et al. (2012).

\section{Results}

\section{Bird community}

A total of 22 bird species were recorded during the study (Appendix 2 of ESM). All of these were observed in Kirkenes, while only 12 were observed in Tana. Fifteen species were classified as ground foraging, while seven were classified as tree foraging. However, tree foraging species were most numerous in terms of counts, mainly due to the brambling (Fringilla montifringilla), common redpoll (Carduelis flammea) and willow warbler (Phylloscopus trochilus), which collectively accounted for about $72 \%$ of the counts in the dataset. The only commonly observed ground-foraging species was the redwing (Turdus iliacus), accounting for roughly $10 \%$ of the counts (Appendix 2 of ESM).

\section{Community response to forest damage in the two locations}

The mean coefficient for the effect of forest damage on abundance in Kirkenes ( $\left.\mu_{\beta 1 \text {,Kirkenes }}\right)$ was slightly negative, with a $95 \%$ posterior interval that narrowly covered zero (Table 2), indicating that the abundance of most bird species was somewhat lower in damaged forest in this location. In accordance with this, the species-specific coefficients for forest damage in Kirkenes were negative for almost all species (Appendix 2 of ESM). However, the negative effects were small in most cases, and the posterior intervals covered zero for all species except the willow warbler. Thus, the predicted abundances of most species were just slightly lower in damaged than in undamaged forest in Kirkenes (Fig. 3; Appendix 2 of ESM). The predicted abundance of the willow warbler, which showed the strongest response, was roughly half as high in damaged forest as in undamaged. The common redpoll also showed a relatively clear response, with a roughly $40 \%$ lower predicted abundance in damaged than undamaged forest. The raw individual counts also suggested that the brambling and redwing showed substantially lower abundances in damaged forest in Kirkenes (Appendix 2 of ESM). 
Table 2 Estimates of community-level hyper-parameters for the submodels of true abundance (log scale) and detection (logit scale) in the hierarchical community model

\begin{tabular}{|c|c|c|c|}
\hline Hyper-parameter & Mean & SD & $95 \% \mathrm{PI}$ \\
\hline \multicolumn{4}{|l|}{ Abundance model } \\
\hline \multicolumn{4}{|c|}{ Intercept Kirkenes } \\
\hline$\mu_{\beta 0, \text { Kirkenes }}$ & -0.70 & 0.52 & $-1.72,0.30$ \\
\hline$\sigma_{\beta 0, \text { Kirkenes }}$ & 1.56 & 0.34 & $1.00,2.33$ \\
\hline \multicolumn{4}{|l|}{ Intercept Tana } \\
\hline$\mu_{\beta 0, \text { Tana }}$ & -2.35 & 0.79 & $-3.83,-0.72$ \\
\hline$\sigma_{\beta 0, \text { Tana }}$ & 2.36 & 0.57 & $1.31,3.61$ \\
\hline \multicolumn{4}{|l|}{ Damage Kirkenes } \\
\hline$\mu_{\beta 1, \text { Kirkenes }}$ & -0.42 & 0.31 & $-1.05,0.19$ \\
\hline$\sigma_{\beta 1 \text {,Kirkenes }}$ & 0.56 & 0.32 & $0.05,1.29$ \\
\hline \multicolumn{4}{|l|}{ Damage Tana } \\
\hline$\mu_{\beta 1, \text { Tana }}$ & 0.05 & 0.29 & $-0.57,0.61$ \\
\hline$\sigma_{\beta 1 \text {,Tana }}$ & 0.38 & 0.31 & $0.01,1.16$ \\
\hline \multicolumn{4}{|l|}{ Detection model } \\
\hline \multicolumn{4}{|c|}{ Intercept Kirkenes } \\
\hline$\mu_{\alpha 0, \text { Kirkenes }}$ & -1.74 & 0.54 & $-2.89,-0.80$ \\
\hline$\sigma_{\alpha 0, \text { Kirkenes }}$ & 1.37 & 0.49 & $0.51,2.44$ \\
\hline \multicolumn{4}{|l|}{ Intercept Tana } \\
\hline$\mu_{\alpha 0, \text { Tana }}$ & -1.48 & 0.83 & $-3.48,-0.30$ \\
\hline$\sigma_{\alpha 0, \text { Tana }}$ & 1.20 & 0.71 & $0.15,2.83$ \\
\hline \multicolumn{4}{|l|}{ Damage } \\
\hline$\mu_{\alpha 1}$ & -0.06 & 0.39 & $-0.87,0.66$ \\
\hline$\sigma_{\alpha 1}$ & 0.57 & 0.35 & $0.04,1.39$ \\
\hline
\end{tabular}

The estimates are presented with SD and $95 \%$ posterior intervals (PI)

However, the detection probabilities of these species were also lower in damaged forest. As a result, the model predicted only slightly lower abundances in damaged than undamaged forest for these two species (Fig. 3). The raw counts of the meadow pipit (Anthus pratensis) in Kirkenes were much higher in damaged than in undamaged forest, but the detection probability of this species was also higher in damaged forest. Thus, the predicted abundances of this species were quite similar between forest types. The total abundance of birds (sum across all species) per site in Kirkenes dropped from a mean of 31.4 individuals to 23.8 individuals when moving from undamaged to damaged forest (Fig. 4a). Judging from the species-specific responses, this drop was mainly driven by the four most abundant species in the data, namely the willow warbler, the brambling, the common redpoll and the redwing (Fig. 3).

In Tana, the mean coefficient for the effect of forest damage on abundance $\left(\mu_{\beta 1 \text {,Tana }}\right)$ was very close to zero (Table 2), indicating that the bird community showed no
Tree foraging
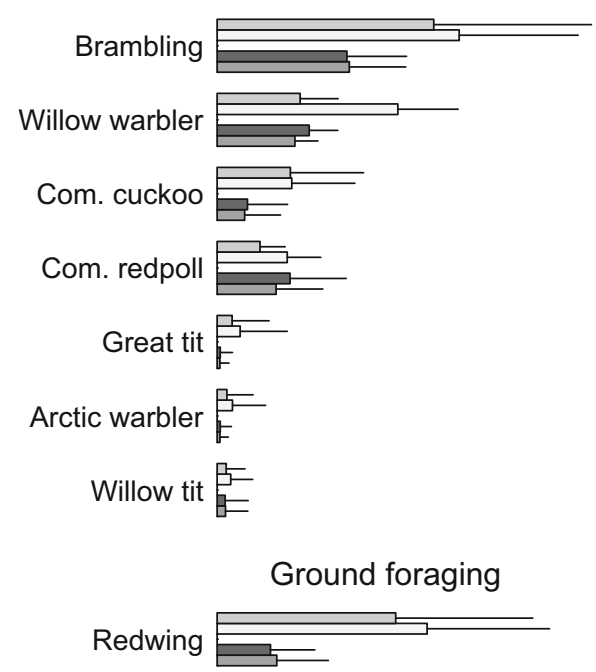

Song thrush $\sqrt{\mathbb{E}}$

Hooded crow $\frac{\square}{E-}$

Meadow pipit $\underset{E}{E}$

Fieldfare $\underline{E}$

Com. redstart 卢

Com. reed bunting 卢

Com. raven $\frac{E}{E}$

Willow ptarmigan $\frac{f-}{\mathbb{E}}$

Com. magpie $\frac{\mathrm{E}}{\mathrm{E}}$

Siberian jay $\mathbb{E}$

Great grey shrike $\mathbb{E}$
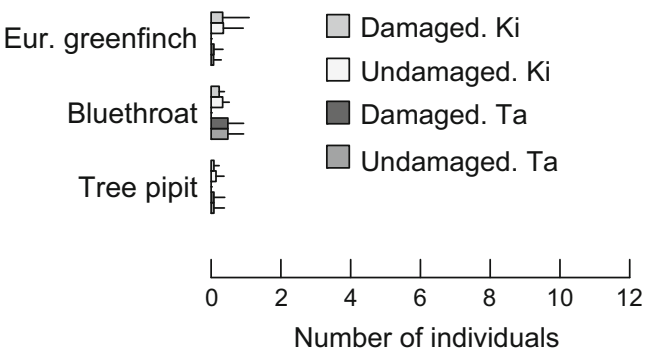

Fig. 3 Abundances predicted from the hierarchical community model (back-transformed from log scale) for individual bird species in damaged and undamaged forest in Kirkenes (Ki) and Tana (Ta). The estimates represent mean abundances across the 3 years of the study for a typical sampling site in each forest type in each location. Error bars represent one SD of the estimates. Note that bars for Kirkenes and Tana are separated within bird each species. Com. common, Eur. European 
Fig. 4 Total abundance (sum across all species) (a, b) and species richness $(\mathbf{c}, \mathbf{d})$ of birds estimated from the hierarchical community model for each sampling site in Kirkenes (a, c) and Tana (b, d), plotted against the airline distance from the first site in each transect. Small symbols represent yearspecific estimates for each site. Large circles represent means across all years and sampling sites in damaged and undamaged forest in each location. Error bars represent $95 \%$ posterior intervals. Sites designated as damaged and undamaged are indicated by grey and white, respectively

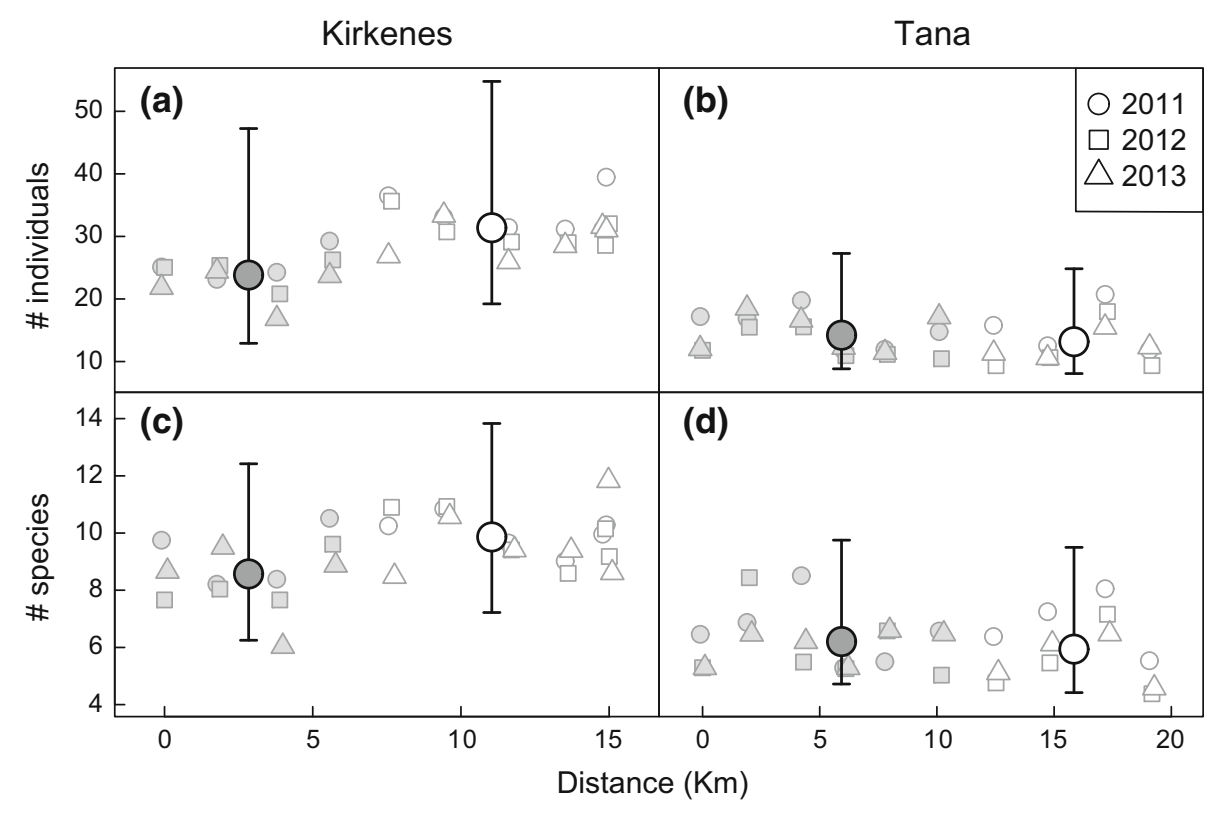

overall directional response to forest damage in this location. As expected from this, the damage coefficients of the individual species varied from slightly negative to slightly positive and were very close to zero in most cases (Appendix 2 of ESM). Also, the posterior intervals covered zero for all species. As a result, the predicted abundances of all species were very similar in damaged and undamaged forest in Tana (Fig. 3). As was the case in Kirkenes, the raw individual counts for the brambling and redwing were substantially lower in damaged than in undamaged forest in Tana (Appendix 2 of ESM). Again, however, the detection probabilities for these two species were lower in damaged forest, resulting in similar predicted abundances for the two forest types. Since the predicted abundances of most species were similar in damaged and undamaged forest, there were no clear differences in the predicted total abundance of birds between the forest types, with the mean number of individuals per site being 13.2 and 14.2 in undamaged and damaged forest, respectively (Fig. 4b). The predicted abundances of most bird species were considerably lower in Tana than in Kirkenes (Fig. 3). Thus, the total abundance of birds was also lower in Tana, particularly in undamaged forest (Fig. 4a, b). There appeared to be no consistent differences in the responses to forest damage between tree- and ground-foraging bird species (Fig. 3; Appendix 2 of ESM).

The patterns in species richness for the two locations were qualitatively quite similar to the patterns in total abundance. In Kirkenes, there tended to be fewer species at sites in damaged forest than in undamaged forest (Fig. 4c). However, this effect was less clear than for total abundance, with the mean species richness per site showing only a slight drop from 9.9 species to 8.6 species when moving from undamaged to damaged forest. In Tana, there appeared to be no consistent differences in species richness between undamaged and damaged forest (Fig. 4d), with the mean species richness per site for the two forest types being 5.9 and 6.2 species, respectively. Just as for total abundance, the species richness in Tana was generally lower than in Kirkenes, especially in undamaged forest (Fig. 4c, d).

\section{Detectability}

The mean coefficient for the effect of forest damage on detectability $\left(\mu_{\alpha 1}\right)$ was very close to zero (Table 2$)$, indicating that there was no consistent tendency among bird species towards higher or lower detectability in damaged forest. In line with this, the coefficients of most individual species were either slightly positive or slightly negative, with posterior intervals that overlapped zero in all cases (Appendix 2 of ESM). The clearest differences in detectability between forest types were shown by the brambling, the redwing, the willow warbler and the meadow pipit, as outlined above. The detection probability of most species was lower than 0.3 in both forest types in both Kirkenes and Tana, and few species showed clear differences in detectability between the two locations (Appendix 2 of ESM).

\section{Discussion}

While several studies have investigated how insectivorous birds respond to increased availability of food during moth outbreaks (Enemar et al. 1984, 2004; Lindström et al. 
2005; Hogstad 2005), there has been no previous research on how bird communities are affected by the severe disturbance that outbreaks can cause to the vegetation in the mountain birch forest. In the present study, we compared bird communities between healthy and recently damaged birch forest to infer the short-term responses of birds to outbreak-induced forest damage. Surprisingly, bird responses to the outbreak were neither very clear nor consistent among our two study locations. Thereby, the pervasive damage that moth outbreaks can cause both to the tree layer and the understorey vegetation does not seem to have dramatic consequences for forest bird communities, at least not in the short term. It would thus appear that these communities have a high degree of resistance [i.e. ability to remain essentially unchanged in the presence of disturbance (Grimm and Wissel 1997)] to outbreak-induced forest damage.

Our inferences in this study assume that sampling sites in damaged and undamaged forest would, in the absence of the outbreak, represent habitats of comparable quality for birds. This is not necessarily true, since the occurrence of the outbreak at given sites could be linked to particular habitat characteristics that are also important for birds. However, our assessment of forest structure showed that the diameter of birch stems and the number of stems per tree did not differ consistently between damaged and undamaged sites in either Kirkenes or Tana (Fig. S1 in Appendix 1 of ESM). This indicates that there are no inherent differences in productivity between damaged and undamaged sites, since the growth form of the mountain birch reflects the productivity of the habitat (birch trees usually have a higher number of smaller stems on poorer soils). Moreover, damaged and undamaged sites showed no consistent differences in topographical variables, including altitude, slope and aspect (Fig. S2 in Appendix 1 of ESM). Thus, the available information does not suggest that damaged and undamaged sites are inherently different.

Birds are highly mobile and could easily move away from outbreak-affected areas if they represented poor habitat. Thus, changes in bird communities in damaged forest would be expected to occur rapidly after outbreaks owing to bird habitat selection. In accordance with this, Gale et al. (2001) found that bird species associated with closed-canopy forest declined in abundance already in the same year as the forest in their study area was being defoliated by gypsy moth (Lymantria dispar). It therefore seems unlikely that we found weak effects of forest damage simply because our study commenced shortly after the outbreak. To the contrary, our results suggest that the effects of forest damage on bird communities may be strongest shortly after an outbreak has occurred. We found a clear effect of forest damage only in Kirkenes, where the outbreak collapsed 2 years before the study. Meanwhile, there was no effect in Tana, where the outbreak collapsed 2 years earlier. The apparent decline in the effect of the outbreak on bird communities over time could possibly be linked to a higher degree of regrowth in the canopy in the older outbreak area in Tana.

The spatial scale on which birds respond to forest damage is also an important consideration. It should be emphasized that all of the damaged sampling sites within a transect were located within a large continuous area of heavily damaged forest. Thus, the level of forest damage around each site was high not only for the $50 \mathrm{~m}$ radius in which we scored the damage of birch stems, but also for a wide array of larger spatial scales, ranging all the way up to the landscape level (i.e. a radius of several $\mathrm{km}$ ). Bird responses to forest damage at much larger spatial scales than our local damage scores should therefore have been reflected in our data. It is therefore unlikely that issues related to the spatial scale of bird responses can explain the weak effects of forest damage in our study.

At least two factors could allow damaged forest to remain acceptable habitat for forest birds. First, individual surviving trees usually occur sporadically throughout an outbreak area. This was also the case in our study (Fig. 2). These trees may provide, for example, nesting sites and hiding places for birds. Larger patches of living trees usually also occur locally within an outbreak area and could serve a similar function. Similar comments apply for the understorey vegetation, which also occurs in undamaged patches of varying size throughout outbreak areas.

A second potentially relevant factor is the dead tree trunks left by an outbreak. There were hardly any fallen trunks in Tana in 2013, i.e. 6 years after the collapse of the outbreak there (OPLV personal observation). Thus, much of the vertical structure of the forest habitat was still maintained. This could be important for bird populations, since the species richness and abundance of forest birds is often strongly linked to structural characteristics of the vegetation, such as canopy height and vegetation density (Müller et al. 2009; Flaspohler et al. 2010; Tattoni et al. 2012). Importantly though, birds are not affected by vegetation structure per se but by related habitat characteristics, such as the availability of nesting, hiding or foraging sites (Zellweger et al. 2013). We do not know whether dead birch trunks can serve such functions. However, Matsuoka and Handel (2007) found that several bird species made surprisingly high use of spruce (Picea spp.) trees killed by bark beetles for nesting. A similar situation may prevail in our system. Cavity nesting birds also benefit from snags created by gypsy moth outbreaks (Showalter and Whitmore 2002), but this has limited applicability to our system, since none of the abundant species in our study are cavity nesters and most birch trunks are too thin for excavation of cavities. Thus, studies of how 
birds utilize the dead birch trunks in our system would be helpful for explaining our results. An alternative would be to repeat our study after trunks have started to fall down, although in this case the results might also be influenced other successional habitat changes.

Recent studies in low-arctic Norwegian tundra by Ims and Henden (2012) and Henden et al. (2013), which included many of the same bird species as the present study, also aid the interpretation of our results. These studies found that the occupancy of many bird species declined dramatically when thicket-forming, 1- to 3-m-tall willow (Salix spp.) shrubs disappeared from the landscape, leaving only field-layer vegetation. This suggests that the vertical structure of the vegetation is indeed important for bird communities in these high-latitude systems. In addition, the fact that several of the most important species in our data (including the willow warbler, common redpoll and redwing) were also common in the treeless habitats studied by Ims and Henden (2012) and Henden et al. (2013) demonstrates that these species are habitat generalists, which are not critically dependent on tall woody vegetation. Virkkala $(1988,1991)$ also showed that the willow warbler and brambling can utilize a wide range of habitats. This flexibility in habitat choice may help explain why the studied bird community appears to be resistant to forest damage caused by moth outbreaks.

An interesting finding from our study is that there were larger differences in total bird abundance and species richness between Tana and Kirkenes than between damaged and undamaged forest within the locations. This suggests that other determinants of landscape-scale habitat selection (Orians and Wittenberger 1991), such as ecosystem-scale productivity differences (as indicated by the diameter and number of tree stems. Fig. S1 in Appendix 1 of ESM) or habitat diversity differences in terms of topography or amount of mires, have stronger effects on the bird community than the disturbance caused by moth outbreaks. This is quite surprising, given the extremely conspicuous impact of outbreaks (Fig. 2c, d).

Since our data were dominated by a few abundant species, our study permits few generalizations about the degree to which bird responses to outbreaks are linked to foraging habits. However, it is noteworthy that the species showing the clearest negative response to forest damage, namely the willow warbler, mainly forages for insects among the foliage of trees. Outbreaks cause severe loss of foliage in the birch forest and hence probably reduce the abundance of insects that are associated with healthy tree canopies. The decline of the willow warbler in damaged forest may thus result from loss of preferred foraging habitat and food resources. Although we also classified the brambling and the common redpoll as mainly tree foraging, these species do more of their foraging on the ground than the willow warbler. This may explain why they were less affected by the outbreak. The same is true for the redwing, which mainly forages on the ground. These results correspond to those of Rabenold et al. (1998), who found that bird species foraging mainly in the canopy showed the strongest declines following mortality of Fraser fir (Abies fraseri) caused by the balsam wooly adelgid (Adelges piceae).

Of all the species in our dataset, only the meadow pipit showed some indication of being more abundant in damaged forest. This general lack of positive responses is quite surprising, since studies in other systems have repeatedly found bird species associated with open or early successional habitats to increase in forest affected by insect outbreaks. However, these increases often appear to have been linked to increases in the density and height of the tall shrub layer in the understorey vegetation (e.g. due to rapid growth of tree saplings or invasion by tall shrub species) (Bell and Whitmore 1997; Canterbury and Blockstein 1997; Rabenold et al. 1998; Gale et al. 2001; Becker et al. 2008). Although the moth outbreak has caused large changes in the field-layer vegetation in our study region, with mass mortality of dwarf shrubs and a shift towards dominance by grass, there have so far been no major changes in the tall shrub layer (Jepsen et al. 2013; Karlsen et al. 2013). This may explain why so few bird species in our study showed a positive response to forest damage. However, this conclusion must be treated cautiously, since many of our species were too rare to make strong inferences about their responses to forest damage. The fact that most rare species were estimated to decline slightly in damaged forest in Kirkenes and show no clear response in Tana is probably caused mostly by Bayesian shrinkage (Iknayan et al. 2014) towards the parameter estimates of the few abundant species in the data. Thus, more targeted studies are required to fully understand how these rare species respond to forest damage.

In conclusion, our study has demonstrated that birds utilize mountain birch forest which has been damaged by moth outbreaks to a surprisingly high degree, suggesting that the studied bird community has considerable resistance to the severe habitat disturbance caused by outbreaks. We suggest that future studies explore the role of surviving trees and dead trunks in maintaining bird populations in damaged forest. We should also emphasize that our study considers only short-term effects and that more long-term studies are needed to gain a thorough understanding of the impacts of outbreaks on bird communities. This is especially important considering the fact that many successional processes, such as the degradation of dead birch trunks and the emergence of new saplings, happen slowly in our cold, high-latitude system. For now, however, our results do not point towards outbreak-induced forest 
damage as a major driver of the recently observed declines of bird populations in Scandinavian mountain birch forest (Lehikoinen et al. 2014).

Acknowledgments We are grateful to Geir Vie for taking bird censuses and to Lauri Kapari for help with establishing the field design. We would also like to thank John-André Henden for providing advice on the analysis and Raimo Virkkala and an anonymous reviewer for commenting on the manuscript. This study was funded by the University of Troms $\varnothing$ and the research council of Norway, with additional support from the Norwegian Institute of Nature Research and the Nordic Centre of Excellence-How to preserve the tundra under a warming climate (NCoE-Tundra) funded by the Norden TopLevel Initiative "Effect studies and adaptation to climate change".

Open Access This article is distributed under the terms of the Creative Commons Attribution 4.0 International License (http://creativecommons.org/licenses/by/4.0/), which permits unrestricted use, distribution, and reproduction in any medium, provided you give appropriate credit to the original author(s) and the source, provide a link to the Creative Commons license, and indicate if changes were made.

\section{References}

Barbosa P, Letourneau D et al (2012) Insect outbreaks revisited. Wiley, New York

Becker DA, Brittingham MC et al (2008) Effects of hemlock woolly adelgid on breeding birds at Fort Indiantown Gap, Pennsylvania. Northeast Nat 15(2):227-240

Bell JL, Whitmore RC (1997) Eastern towhee numbers increase following defoliation by gypsy moths. Auk 114(4):708-716

Canterbury GE, Blockstein DE (1997) Local changes in a breeding bird community following forest disturbance (Cambios Locales en Una Comunidad de Aves en Reproduccion Tras un Disturbio Forestal). J Field Ornithol 68(4):537-546

Chandler RB, King DI et al (2013) A small-scale land-sparing approach to conserving biological diversity in tropical agricultural landscapes. Conserv Biol 27(4):785-795

Dennison PE, Brunelle AR et al (2010) Assessing canopy mortality during a mountain pine beetle outbreak using GeoEye-1 high spatial resolution satellite data. Remote Sens Environ 114(11):2431-2435

Enemar A, Nilsson L, Sjöstrand B (1984) The composition and dynamics of the passerine community in a subalpine birch forest, Swedish Lapland. A 20-year study. Ann Zool Fenn 21:321-338

Enemar A, Sjöstrand B, Andersson G, Tv Proschwitz (2004) The 37-year dynamics of a subalpine passerine bird community, with special emphasis on the influence of environmental temparature and Epirrita autumnata cycles. Ornis Sveica 14:63-106

Flaspohler DJ, Giardina CP et al (2010) Long-term effects of fragmentation and fragment properties on bird species richness in Hawaiian forests. Biol Conserv 143(2):280-288

Gale GA, DeCecco JA et al (2001) Effects of gypsy moth defoliation on forest birds: an assessment using breeding bird census data (Efectos de la Defoliación por Lymantria dispar en Aves Bosquecinas: Una Evaluación Usando Datos de los Censos de Navideños de Aves). J Field Ornithol 72(2):291-304

Gelman A, Hill J (2007) Data analysis using regression and multilevel/hierarchical models. Cambridge University Press, Cambridge

Grimm V, Wissel C (1997) Babel, or the ecological stability discussions: an inventory and analysis of terminology and a guide for avoiding confusion. Oecologia 109(3):323-334
Hausner VH, Yoccoz NG et al (2003) Selecting indicator traits for monitoring land use impacts: birds in northern coastal birch forests. Ecol Appl 13(4):999-1012

Henden J-A, Yoccoz NG et al (2013) How spatial variation in areal extent and configuration of labile vegetation states affect the riparian bird community in Arctic Tundra. PLoS One $8(5): \mathrm{e} 63312$

Hogstad O (2005) Numerical and functional responses of breeding passerine species to mass occurrence of geometrid caterpillars in a subalpine birch forest: a 30-year study. Ibis 147(1):77-91. doi:10.1111/j.1474-919x.2004.00338

Iknayan KJ, Tingley MW et al (2014) Detecting diversity: emerging methods to estimate species diversity. Trends Ecol Evol 29(2):97-106

Ims RA, Henden J-A (2012) Collapse of an arctic bird community resulting from ungulate-induced loss of erect shrubs. Biol Conserv 149(1):2-5

Jepsen JU, Hagen SB et al (2008) Climate change and outbreaks of the geometrids Operophtera brumata and Epirrita autumnata in subarctic birch forest: evidence of a recent outbreak range expansion. J Anim Ecol 77(2):257-264

Jepsen JU, Hagen SB et al (2009a) Phase-dependent outbreak dynamics of geometrid moth linked to host plant phenology. Proc R Soc B Biol Sci 276(1676):4119-4128

Jepsen JU, Hagen SB et al (2009b) Monitoring the spatio-temporal dynamics of geometrid moth outbreaks in birch forest using MODIS-NDVI data. Remote Sens Environ 113(9):1939-1947

Jepsen JU, Kapari L et al (2011) Rapid northwards expansion of a forest insect pest attributed to spring phenology matching with sub-Arctic birch. Glob Chang Biol 17(6):2071-2083

Jepsen J, Biuw M et al (2013) Ecosystem impacts of a range expanding forest defoliator at the forest-tundra ecotone. Ecosystems 16(4):561-575

Karlsen S, Jepsen J et al (2013) Outbreaks by canopy-feeding geometrid moth cause state-dependent shifts in understorey plant communities. Oecologia 173(3):859-870

Kéry M, Royle JA (2009) Inference about species richness and community structure using species-specific occupancy models in the National Swiss Breeding Bird Survey MHB. In: Thomson D, Cooch E, Conroy M (eds) Modeling demographic processes in marked populations, vol 3. Springer, New York, pp 639-656

Lehikoinen A, Green M et al (2014) Common montane birds are declining in northern Europe. J Avian Biol 45(1):3-14

Lehnert LW, Bässler C et al (2013) Conservation value of forests attacked by bark beetles: highest number of indicator species is found in early successional stages. J Nat Conserv 21(2):97-104

Lindström ^ (1987) Breeding nomadism and site tenacity in the brambling Fringilla montifringilla. Ornis Fenn 64:50-56

Lindström Å, Enemar A, Andersson G, Tv Proschwitz, Nyholm NEI (2005) Density-dependent reproductive output in relation to a drastically varying food supply: getting the density measure right. Oikos 110(1):155-163. doi:10.1111/j.0030-1299.2005. 13828.x

Man R, Rice JA (2010) Response of aspen stands to forest tent caterpillar defoliation and subsequent overstory mortality in northeastern Ontario, Canada. For Ecol Manag 260(10): 1853-1860

Matsuoka SM, Handel CM (2007) Nesting ecology of boreal forest birds following a massive outbreak of spruce beetles. J Wildl Manag 71(1):51-63

Moulinier J, Lorenzetti F et al (2013) Effects of a forest tent caterpillar outbreak on the dynamics of mixedwood boreal forests of eastern Canada. Ecoscience 20(2):182-193

Müller J, Bußler H et al (2008) The European spruce bark beetle Ips typographus in a national park: from pest to keystone species. Biodivers Conserv 17(12):2979-3001 
Müller J, Moning C et al (2009) Using airborne laser scanning to model potential abundance and assemblages of forest passerines. Basic Appl Ecol 10(7):671-681

Orians GH, Wittenberger JF (1991) Spatial and temporal scales in habitat selection. Am Nat 137:29-49

R Development Core Team (2012) R: a language and environment for statistical computing. R Foundation for Statistical Computing, Vienna

Rabenold KN, Fauth PT et al (1998) Response of avian communities to disturbance by an exotic insect in spruce-fir forests of the southern Appalachians. Conserv Biol 12(1):177-189

Ratcliffe DA (2005) Lapland: a natural history. Yale University Press, New Haven

Royle JA (2004) N-mixture models for estimating population size from spatially replicated counts. Biometrics 60(1):108-115

Showalter CR, Whitmore RC (2002) The effect of gypsy moth defoliation on cavity-nesting bird communities. For Sci 48(2):273-281

Snow DW, Perrins CM et al (1998) The birds of the western palearctic. Oxford University Press, Oxford

Sturtz S, Ligges U et al (2005) R2WinBUGS: a package for running WinBUGS from R. J Stat Softw 12(3):1-16
Tattoni C, Rizzolli F et al (2012) Can LiDAR data improve bird habitat suitability models? Ecol Model 245:103-110

Virkkala R (1988) Foraging niches of foliage-gleaning birds in the northernmost taiga in Finland. Ornis Fenn 65:104-113

Virkkala R (1991) Spatial and temporal variation in bird communities and populations in north-boreal coniferous forests: a multiscale approach. Oikos 62(1):59-66. doi:10.2307/3545446

Weed AS, Ayres MP et al (2013) Consequences of climate change for biotic disturbances in North American forests. Ecol Monogr 83(4):441-470

Yamaura Y, Royle JA et al (2012) Biodiversity of man-made open habitats in an underused country: a class of multispecies abundance models for count data. Biodivers Conserv 21(6): $1365-1380$

Yang LH (2012) The ecological consequences of insect outbreaks. Insect outbreaks revisited. Wiley, New York, pp 197-218

Zellweger F, Braunisch V et al (2013) Remotely sensed forest structural complexity predicts multi species occurrence at the landscape scale. For Ecol Manag 307:303-312

Zipkin EF, DeWan A et al (2009) Impacts of forest fragmentation on species richness: a hierarchical approach to community modelling. J Appl Ecol 46(4):815-822 